\title{
Pupil Perspectives on the Contribution of Information and Communication Technology to Teaching and Learning in the Secondary School
}

\author{
Rosemary Deaney, Kenneth Ruthven and Sara Hennessy
}

Research Papers in Education, 2003, 18 (2), 141-165

\begin{abstract}
This study explores pupils' views of the use of information and communication technology (ICT) within subject teaching and learning. Members of three year cohorts (Years 8,10 and 12) in six English secondary schools took part in focus group interviews during the first half of 2000. The views elicited in the course of the 27 interviews are summarised in terms of six themes. Pupils saw computer-based tools and resources as helping not just to effect tasks and improve presentation, but also to refine work and trial options. They associated the use of such tools and resources with changes in working ambience and classroom relations, as well as with raised interest and increased motivation on their part. Finally, while pupils welcomed opportunities for independent working mediated by ICT in which they could engage more directly with appropriately challenging tasks, they were concerned that this reshaping of learning might be displacing valuable teaching.
\end{abstract}

Keywords: Information technology; Computer uses in education; Learner characteristics; Student attitudes; Secondary education; England; Research report.

\section{INTRODUCTION}

Over the past two decades, Information Technology (IT) has broadened to become Information and Communication Technology (ICT), and has become better established within schools (Abbott, 2001). Many claims have been made about its potential contribution to pupils' learning (Pachler, 1999) and official rhetoric has presented it as set to 'transform education' (Blair, 1997). Much current policy and practice reflects a technocratic determinism in which technology is seen unproblematically as providing relatively immediate tools for teachers and students, and its use as calling primarily for development of technical skills. However, others see successful educational applications of the computer as involving a complex interplay of context, people, activities, machines and available software within specific settings (Noss \& Pachler, 1999, Leach \& Moon, 2000). While quality and level of ICT resource continue to improve in many schools, provision of equipment alone is likely to be of limited value unless more is understood about the interactions and processes engendered by using technology in different settings, and how pedagogical strategies to enhance students' learning might be developed effectively through them.

Students constitute a significant group within this social system, and their perspectives play an important part in framing the activity that takes place in school settings. Indeed, it has been argued that young people should be seen as active participants in shaping social and educational processes rather than viewed as passive recipients of them (Pollard \& Tann, 1993). Research has demonstrated that, from an early age, young people are capable of insightful and constructive analysis of their experience of learning in school and are able to comment on teaching approaches and contexts that are helpful in their learning (Brown \& McIntyre, 1993; Harris et al., 1995; McCallum et al., 2000; Rudduck \& Flutter, 2000). A key component in acquiring such understanding may be attention to 
the 'pupil voice' (Keys \& Fernandes, 1993; Blatchford, 1996; Rudduck et al., 1996). Rudduck and Flutter (op cit) maintain that 'we need to tune in to what pupils can tell us about their experiences and what they think will make a difference to their commitment to learning and, in turn, to their progress' (p. 75). Recent research on pupils' perspectives in the UK has been linked either to the development of school-based strategies based on consultation with pupils on effective classroom practice, or to aspects of curricular evaluation (see Lord and Harland (2000) for a review) but few studies have focused specifically on secondary pupils' views on their current classroom use of ICT in teaching and learning. Where students' perspectives have provided the focus for such inquiry in other educational settings (for example the Canadian technology-enhanced Secondary Science instruction (TESSI) project), pupils' enhanced participation in learning activities and their development of successful learning strategies were attributed to the combined influences of - and interactions between - the technologies employed and the pedagogical and social milieu of the classroom (Pedretti et al., 1998).

The popular image of young people - the 'screenagers' referred to by Rushkoff, (1997) - growing up in an increasingly technology-dependent society, connected by sophisticated telecommunication networks in a culture mediated by television and computer, is that of natural computer users from a 'digital generation'. Recent studies (Holloway \& Valentine, 1999; Becta, 2001; Facer et al., 2001; Wellington, 2001) have begun to examine the nature and extent of young people's use of ICT outside school and the influence that it may have upon their learning with ICT in school. Whilst results indicate that some children (often those who use computers extensively at home) are capable of integrating their use of ICT in balanced and sophisticated ways (Furlong et al., 2000), the indications are that this further accentuates inequities between such young people and their peers who lack similar access to these technologies. Findings also show that whilst boundaries between home knowledge and school knowledge are being eroded, learners' experience of ICT takes on a different character depending upon the context of its use. Furlong et al (op cit) found that at home, young people tend to control their own time, how they use technology and the content of what they do. In school, however, the locus of control lies elsewhere; emphasis is on learning activities managed by the teacher, metered by timetable constraints, designed to meet curriculum criteria and attainment targets and incorporate the mandatory use of ICTs.

\section{CONTEXT AND DESIGN OF THE STUDY}

In this study, we examine the perspectives of pupils in six English secondary schools on the contribution of ICT to teaching and learning. These schools were in research partnership with the University of Cambridge Faculty of Education, and they had identified the use of ICT to support subject teaching and learning as a common priority for development. The opening (formative) phase of the resulting programme of research and development sought to identify and analyse what teachers and pupils saw as successful practice in using ICT to support teaching and learning, with a view to informing a second (developmental) phase in which promising approaches would be developed and investigated in greater depth. In this particular study, we draw on interviews conducted with pupils during the first half of 2000, as part of the opening phase of the project, to explore their experience of ICT in teaching and learning.

\section{Participating schools}

All these maintained secondary schools were located within 80 kilometres of Cambridge. Basic information about each is given in Table 1. Pseudonyms have been adapted from 
official designations, and the corresponding abbreviated codes have been adopted to indicate sources for quoted material. Although some of the schools had - or aspired to specialist status as indicated in their pseudonyms, none operated a selective admissions policy.

Table 1: Profiles of the participating schools

\begin{tabular}{lccccc}
\hline School [Code] & $\begin{array}{c}\text { Age range of } \\
\text { students }\end{array}$ & $\begin{array}{c}\text { Gender of } \\
\text { students }\end{array}$ & $\begin{array}{c}\text { Number of } \\
\text { students } \\
\text { enrolled }\end{array}$ & $\begin{array}{c}\text { Proportion of } \\
\text { students } \\
\text { entitled to free } \\
\text { school meals }\end{array}$ & $\begin{array}{c}\text { Proportion of } \\
\text { students } \\
\text { achieving } \\
\text { GCSE exam } \\
\text { benchmark }\end{array}$ \\
\hline Community College [CC] & $11-16$ & Mixed & 961 & $15 \%$ & $54 \%$ \\
Girls School [GS] & $11-18$ & Female & 1050 & $13 \%$ & $67 \%$ \\
Media College [MC] & $13-18$ & Mixed & 1500 & $5 \%$ & $69 \%$ \\
Sports College [SC] & $11-16$ & Mixed & 1023 & $2 \%$ & $74 \%$ \\
Technology College [TC] & $11-16$ & Mixed & 1237 & $5 \%$ & $68 \%$ \\
Village College [VC] & $11-18$ & Mixed & 1305 & $5 \%$ & $51 \%$ \\
\hline
\end{tabular}

Further relevant data have been extracted from official performance tables (dated 2000) and inspection reports on individual schools (dated between 1996 and 1999). The proportion of students entitled to free school meals is a standard indicator of social disadvantage: two schools - Community College and Girls School - lay close to the national median for schools (14\%) on this index; and the remainder showed markedly lower levels of disadvantage. The proportion of students gaining the benchmark of 5 or more higher-level GCSE examination passes at age 16 is a standard indicator of academic success: two schools - Community College and Village College - stood a little above the national median for schools (45\%) on this index; and the other five showed markedly higher levels of academic success. Against national norms, then, the schools in this opportunity sample were relatively socially advantaged and academically successful. There was considerable variation in ICT provision amongst the six schools. Media College and Technology College were the most highly resourced -providing, for example, dedicated departmental ICT rooms for Mathematics and Science. In all of the schools, however, ICT use within most subject teaching and learning was greatly dependent upon opportunistic access to computer rooms that were already heavily scheduled for specialist ICT courses or vocational options. Consequently, although some planned and effective use of ICT was evident within the teaching and learning of core and foundation subjects, recent inspection reports indicated that such development was uneven within all six schools.

\section{Investigative strategy}

Because the research partnership aims at promoting cultural change within participating schools, and this particular project at supporting pedagogical development, it was important to adopt investigative approaches likely to create institutional conditions conducive to working towards such changes. Consequently, the first phase of the research employed group interviews of teachers - in their subject departments - and of pupils - by year group.

The 'focus group' method (Kitzinger \& Barbour, 1999) is increasingly current in social science and educational research. When used appropriately, it is versatile and costeffective compared with individual interviews, and most importantly, a powerful means 
of provoking informative interaction between participants. Focus groups allow the researcher to explore different perspectives within a social network and how these are articulated, challenged and developed through interaction and in relation to group norms.

Three separate year cohorts were selected to participate in the pupil study. As group interviews were scheduled during lesson time, those cohorts involved with national testing and external examinations - Years 9, 11 and 13 - were avoided in order to minimise disruption to their studies. Equally, Year 7 was excluded because of the recency of entry to secondary education of its members. In each school, then, two groups of pupils were interviewed within each available year cohort from Years 8, 10 and 12. Teachers were asked to select at random two pupils from each tutor group within the target year by choosing the boy and girl whose surnames were nearest the midpoint position in the alphabetic class list. The resulting 27 focus groups - formed by combining nominees from two or more tutor groups - varied in size between 4 and 8 pupils.

Group interviews were convened by members of the research team. Questions were devised to elicit examples of where ICT had helped - or could in future help - to make learning more successful, to draw on experiences of ICT use - both in and out of the classroom - and to explore how learning is - or might be - changed by ICT. Out of the twenty-eight focus group interviews that took place, one was lost due to technical failure; analysis therefore relates to data from twenty-seven groups. All group interviews were audio-taped, transcribed and edited into short units of talk, separated where speaker or subject switched. The edited transcripts were imported into a computer database (QSR NUD*IST) and selectively coded in a recursive process of constant comparison (Glaser $\&$ Strauss, 1967) through which salient themes running across the data corpus were identified and organised.

\section{FORMS OF ICT USE REPORTED}

At the start of each interview session, pupils were invited to supply examples of ICT use within their lessons. Broadly, pupils reported encountering two types of ICT resource. First was a range of what could be described as ICT tools: notably wordprocessing and publishing packages for purposes of writing and illustrating documents, calculators and spreadsheets for purposes of analysing and graphing data, CD-ROM encyclopedias and the Internet for puposes of seeking and abstracting information, all used across a range of subjects; as well as more specialised tools for processes such as function graphing in Mathematics, data-logging in Science, computer-aided design in Technology, electronic circuit simulation in Science and Technology, and composition in Music. Second was a range of what could be termed courseware and revision resources; vocabulary packages in Languages; puzzles, games and drills - such as SMILE - in Mathematics; and revision packages and websites - notably BiteSize - across a range of subjects.

An analysis was carried out of the first three subjects mentioned in each interview (Table 2). The resulting evidence should not be taken as indicative of the relative extent of ICT use in subject areas, but simply as showing the contexts that came to mind most readily for pupils. This evidence indicated that Mathematics was most frequently cited, followed by IT (as a separate subject) - both cited in more than half the interviews followed followed by English and Science - both cited in more than a third of interviews. However, the tabulated evidence also demonstrates that the transcripts incorporated examples from across the secondary curriculum. 
Table 2: Frequency of citation of subject areas in interviews

\begin{tabular}{lcc}
\hline Subject area & $\begin{array}{c}\text { Number of interviews } \\
\text { in which amongst first } \\
\text { three subjects cited }\end{array}$ & $\begin{array}{c}\text { Proportion of } \\
\text { interviews in } \\
\text { which so cited }\end{array}$ \\
\hline Mathematics & 16 & $59 \%$ \\
Information Technology (as separate subject) & 15 & $56 \%$ \\
English & 10 & $37 \%$ \\
Science & 9 & $33 \%$ \\
Technology & 7 & $26 \%$ \\
Humanities (Geography, History and Religious Studies) & 6 & $22 \%$ \\
Art and Graphics & 5 & $19 \%$ \\
Modern Languages (French and German) & 5 & $19 \%$ \\
Other (including Business, PSE) & 8 & $30 \%$ \\
\hline
\end{tabular}

\section{PERCEPTIONS OF THE CONTRIBUTION OF ICT}

The main analysis of the transcripts focused on what pupils had to say about the contribution - actual or potential - of ICT to teaching and learning. The ideas running across the groups can be summarised conveniently in terms of six major organising themes which will be discussed in turn:

- Tasks effected

- Refinement assisted

- Ambience altered

- Motivation changed

- Learning reshaped

- Teaching displaced

\section{Tasks effected}

This theme concerns the contribution of ICT use to effecting tasks encountered within academic work. Pupils in all year groups and schools reported how use of ICT tools enabled them to carry out such tasks with ease, quickly and reliably, and to a high standard.

At a basic level, a comment on data logging in Science pointed to the ease, speed and accuracy of the process:

Well, it made it quite easy to do and quick. You could read the graphs easily and you get accurate results. Like if we used stopwatches they wouldn't be very accurate, but there's no error when you use light gates. [TC/10]

At a more sophisticated level, a comment on function graphing in Mathematics indicated how saving time could permit a more expansive and sophisticated approach to tasks:

It saves time drawing out every single graph, because that takes a lot of time, and you can look at more examples, you can look at examples over each other so you can see the difference between them. [SC/10] 
All year groups alluded to the way in which ICT could facilitate quality of written presentation:

If you want your writing to be neat then you're going to take time on each letter, make sure everything is perfect. You don't need to do that on a computer, you just type and spell check and it does it for you. [VC/12]

However, it was Year 8 pupils who most often spoke of ICT helping them to produce neater and tidier work which was more 'professional' in appearance, sometimes directly associating this with gaining 'more marks':

It's handy because you can get everything done on the computer and it looks all professional... And it also helps because it improves your marks if you've done it on the computer / I've found that. Because if you do it on the computer you get more marks than if you write it out by hand. [TC/8]

Pupils in most schools emphasised the practical functionality of templates and wizards:

You have, like, questions and then you answer them. It has multiple choice sort of thing. And then it gives you the newspaper that you want. And then you just type in what you want... Otherwise we would have to lay all the newspaper stuff out and what we wanted, and that would take ages / Or we could hand write it but that would look messy. / And it wouldn't look as neat and professional. [CC/8]

However, some commented on the importance of remaining in expressive control of their work:

For me I find that whatever I'm doing I like that feeling of being able to shape it how I want it to be. $[\mathrm{CC} / 10]$

Equally, there were comments on how computer-generated work - however accomplished - lacked the personalised qualities of hand-crafted material:

I prefer actually producing it myself with my handwriting. I think it looks nicer than just black, typed, boring, because everyone's is the same. [VC/8]

ICT applications remain largely dependent upon keyboard input. Older pupils reported the benefits of having good keyboard skills:

If you know your way around a keyboard it's pretty quick. It's much faster then writing. [VC/12]

However, some younger students felt hampered by lack of such proficiency:

I prefer doing it on the computer, but I just write quicker than when I type [GS/8]

Pupils suggested a need for more sustained training in this area. Indeed members of two groups reported that they were so slow they sometimes resorted to parental help:

I think we should have had typing lessons more as well. / Yes, we had that in Year 7 for about half a year. / The very few times I do use it, it takes me four hours to write a page. I just get my Mum to do it... But some people I know... they can really type fast. You watch them and you think "I wish I could do that". [GS/10]

Similarly, pupils felt that additional training would enable them to take better advantage of the technology:

We need to know how to work [Excel] first. They say, in Maths "Do these graphs" - we could do it like that if we know how to use it prior to the lesson. [VC/10]

The majority of pupils interviewed had computers at home - and used them for gameplaying, homework and the Internet (although the latter was often restricted by cost). Some felt that IT skills gained in this context supported their use of technology in school:

And some of us have computers at home so we learn things there and bring them to school [GS/8]

You learn a lot at home. You dare do more stuff at home. [TC/10]

...because not everybody is at the same level. Some people don't like playing with computers, they don't know what to do, they haven't got a clue, they're used to just writing in their book. Where others are, like, really good at it and have taken to it. [VC/10] 
In seeking information, the Internet was seen as particularly valuable in accessing current or specialist material:

If it's really up to date the Internet's got it on there, or if it's something like a specialist subject, which they're aren't many books about, or books here about. [TC/10]

Searching the Internet was frequently compared with book-based research. Access to information on the Internet was represented by some pupils as more direct:

Well, rather than [with books] having to go through loads and loads of pages of really difficult stuff and finding a couple of good bits and then pulling them out, it [the Internet] just gives you what you want and then you can read it, change it. [TC/10]

Equally, books were represented by other pupils as a more contained and structured source of information:

I prefer looking in books and things because it's quicker and you don't get lost. You can just go to the index, whereas if you search for something [on the Internet] you come up with lots of things that aren't quite related, they just had that particular word. [SC/10]

Both these comments are revealing about the search strategies available to the pupils making them.

In summary, pupils valued ICT tools as enabling them to carry out academic tasks easily, rapidly and reliably, yielding results of high quality. Nevertheless, they experienced situations where they were hampered in exploiting this potential because of lack of proficiency in using the tools. This might be seen as a predictable consequence of their largely occasional and irregular opportunities to make use of ICT in many subject areas, inhibiting their development of the constituent elements of digital literacy (Gilster, 1997; Selwyn, 1997; Brindley, 2000). Although pupils generally welcomed the way in which ICT tools effected tasks, some were concerned to retain control over their work. Equally, although the high quality achievable when using ICT tools was generally appreciated, this also accentuated what some pupils saw as the more personalised character of hand-crafted material.

\section{Refinement assisted}

This theme concerns the contribution of ICT use to refining creations in the course of academic work. It goes beyond the idea of simply effecting tasks to focus on the scope that ICT provides for trialling options and revising attempts, enabling ideas to be essayed and improved.

Across all years and schools pupils remarked on how writing with ICT made various types of modification much easier. One aspect was simply correcting and erasing mistakes:

I prefer using computers because maybe you've made a mistake when you're writing it by hand and then you'd have to go back and maybe Tippex it, change it, and then it looks messy, whereas on the computer you can just delete it if you want to undo something. [GS/10]

Equally, many pupils saw the feedback provided by spelling and grammar checkers as helpful:

I think it's good as well the way it underlines in green if you do a grammar problem or in red if you spell something wrong. That helps. [VC/10]

Some, indeed, atttributed considerable capacities to such tools:

Because when you make a mistake in a sentence, the computer will correct you and tell you how to write a sentence properly. [VC/8]

Others were more alert to limitations, and active in managing them:

I always think the spell-check's a bit stupid. You have to double-check it. [GS/12] 
Another aspect of writing with ICT to which pupils drew attention was the relative ease with which texts could be reorganised:

I'd rather type an essay than write it because, if you write it, if you want to make a change, if you want to move a block of text somewhere else and you're writing it, you can't do it. $[\mathrm{CC} / 10]$

Equally, the ready revisability of texts affected attitudes to re-drafting:

It's easier to re-draft. Because if you write it out by hand and the teacher says redraft it you're a bit reluctant to, whereas if it's on the computer you just open the file and change it. [TC/10]

More fundamentally, some pupils suggested that the flexibility available when writing with a computer assisted the creative process of composition:

I find it easier just going in and typing, especially if we're doing like a creative piece like a story because / You're making it up as you go along / No, because I think about my ideas and then I can put them down and then I read through it and the bits where I think it sounds a bit weird than I can delete all that out and if I suddenly come up with more ideas I can just add it, whereas if you're doing it on a piece of paper you have to keep doing those little stars and writing it underneath. [GS/8]

Moving away from writing, pupils offered a variety of examples where using other types of ICT tool allowed them to experiment in order to try out and evaluate different results:

I've got a friend who does Art and she can scan her work onto the computer and she can, sort of, test what would happen if she did a different effect to it. She can decide whether she likes it or not, or what she likes best. Different colours and tones you can check out by doing that first, rather than going straight into it and coming out with something that took ages that could not be what you wanted. [GS/12]

Equally, use of ICT to generate examples and explore patterns could assist analysis:

If you have something that you can use to draw a graph you can then experiment with it. If you're drawing a graph of $y$ equals sine $x$ you could change it to a graph of $y$ equals sine $2 x$. / It's much easier. / You'd see what it looked like immediately, instead of having to draw the whole thing again. / You could compare relationships. [CC/10]

In summary, pupils appreciated the way in which working with ICT facilitated various forms of correction and revision, experimentation and exploration, supporting the refinement of artefacts and ideas. Such ideas were prominent in relation to writing with computers, extending beyond the polishing of texts to their reworking. This resonates with research studies which have suggested that word processing - compared to handwriting - may engender a different writing process where pupils tend to continuously modify their drafts in response to their own thoughts and as a result of conversations with others (Norris et al., 1999).

\section{Ambience altered}

This theme concerns the association between ICT use and altered working ambience and classroom relations. Pupils in all groups commented on differences between ordinary lessons and those using computers and other technologies.

Typically lessons using computers took place in specific resource areas or computer suites. Approving reference was made to such changes of location:

If you come into the resources or IT suites then it's different scenery and you get more involved because you're not sitting in the classroom just getting on with it. It's different. [VC/10]

Such lessons were often seen as more 'exciting' and 'fun' than others:

It's more exciting, because you're there with a computer rather than pen and paper... It's more fun to use because you don't have to sit there and write. [MC/10] 
Differences between ordinary lessons and those using computers were characterised in terms of changed patterns of activity:

Because it's a change, isn't it? All we do in lessons is copy out of textbooks, answer questions or copy off the board, just into a book and that's all we do. So if I go onto a computer it would just be different. [MC/10]

An important aspect of this was a reduction in the amount of writing required:

It was basically what we were doing on paper, but on a calculator. It made you concentrate because it was different; it helped me a lot because I was using a different thing to what I was used to, instead of just writing it down. [VC/8]

However, pupils recognised that as novelty faded, computer use itself might become routine:

I suppose that if you did do it all the time it would be just normal. If you didn't type on the computer all the time it would be something that's special, something that's different.[VC/10]

Pupils welcomed what they saw as a tendency of teachers to adopt a more relaxed manner in lessons involving ICT :

Because we're in the computer room and not sitting at our desks and acting bored I think they wander around and if we're playing the SMILE game in Maths sometimes they'll play a game with you and they're more friendly than in the classroom. [GS/8]

The typical layout of computer rooms was seen as contributing to this reduction in formality

Whereas in a normal classroom environment you face the teacher, if the pupils face away from the teacher, or the person they're meant to be looking at, then I think that causes a less formal environment. [CC/10]

However, greater informality on the part of teachers was seen as having the potential to trigger misconduct:

I think pupils get the idea that if their teacher's more relaxed they'll take that as an incentive to do what they want. [CC/10]

Indeed, pupils in every school complained that lessons involving computers tended to engender a degree of misbehaviour:

Most of the time when we are using computers... people don't always do their work and take it seriously. If we used it a lot more often, people would get into the habit of it and treat it like you do when you come in and sit down in a classroom. [TC/10]

Group size and resource provision meant that working in pairs on the computer was common across all participating schools. Here, the sharing of machines appeared to be more often a routine matter of practical expediency than a strategy designed to promote and support genuine collaborative engagement, and this is reflected in pupils' comments. Sometimes this was seen positively, in terms of mutual support:

Sometimes it's better working in pairs because you help to explain to each other. Say if you don't understand something and your partner does, they explain it to you and vice-versa. [TC/10]

In Science in particular, co-operative working was an accepted part of normal laboratory practice:

Plus the person is there to help you, so if you need something you can say, "oh, quickly, go and get me this", or, "hand me that" and you're much more organised. [GS/12]

More often, though, pupils complained about pair working. Younger groups in all schools spoke of resulting distraction and unequal task distribution:

I think I probably talk more when I'm on the computers because there's usually one between two or something, so one of you works and the other one relaxes or talks or whatever. You're spending less time doing work. / I hate that because you never know what to do. When the other person is on the computer, I just sit there and don't know what to do. [VC/8] 
In summary, pupils perceived lessons where technology was in use as having distinctive features. Where interaction with a computer replaced customary routines notably notably involving listening to the teacher and writing by hand - classwork was seen as more exciting and fun. Nevertheless, pupils recognised that as its novelty faded, such computer use might itself come to seem routine. Relations with teachers were seen as more relaxed although this could trigger misconduct. While working in pairs at a computer was common, this was largely a matter of expediency. Consistent with previous research, pupils saw such pairs as a means of sharing limited computer expertise (Doornekamp, 1993), but not in terms of more fully collaborative working, something readily explicable in terms of the typical tasks in hand and the wider social organisation of classroom activity (Underwood, 1998).

\section{Motivation changed}

This theme concerns the association between ICT use and changed motivation. Across schools, pupils linked the altered classroom ambience associated with ICT use to raised interest and increased motivation - as already illustrated in the preceding thematic section - and pointed to ways in which the scope for effecting tasks and refining creations with ICT use - as examined in the two opening thematic sections - alleviated potentially demotivating factors.

Educational software packages designed - or perceived as games were popular with younger pupils, whereas use of ICT tools could be seen as less attractive:

When Miss says we're going to go on the SMILE programs everyone's like oh yes, that's really good. But if they say we've got to do stuff in Excel we don't really want to do that. So they should make it more fun with games. [GS/8]

A key motivating quality of ICT-mediated work was interactivity:

Sometimes it can get a bit boring just sitting there listening to the teacher, looking at the board. It would be good if you could actually have an interactive program on the computer where you can click on parts of the body where it actually talks to you and you can actually see what it does, rather than just seeing a picture on the board. [VC/10]

Correspondingly, pupils noted the motivational power of interactive simulations involving intriguing practical challenges:

On Encarta there's this thing and you have to make it move around the Earth and you have to try and get the orbit right at the right speed, so you're learning while you're trying to smash it into the Earth as well. So you're learning about orbits and stuff, but you're still doing something fun. It makes it seem less boring than just copying it out of a book. [TC/10]

Pupils from all schools spoke of the potential of computer tools to help bypass difficulties and weaknesses experienced in writing - and drawing - by hand. For example, they saw the capacity to produce legible script as beneficial, particularly as regards treatment of their work by teachers:

Especially for people who have got messy handwriting... it's easier on the computer... The teacher sometimes marks it wrong because the teacher can't understand the word... and sometimes you can't read your own writing. [GS/8]

Similarly, pupils hinted at how the ease and precision with which graphs and technical drawings could be produced on the computer made such tasks less of a 'struggle':

I think that with graphs and things it's much easier on the computer because some people struggle doing it by hand and it's much simpler doing it on a computer. [GS/10]

Equally, they pointed to the discouragement associated with inaccuracies and mistakes when working by hand:

They're more accurate than if you just draw on a piece of paper, because if you're drawing you can make mistakes and that would just put you off. [SC/10] 
Pupils also suggested that the greater capacity to identify and correct errors diminished the scope for criticism of their work by teachers:

I think when I do something by hand there's more room for criticism because it's like, oh, you've smudged a line, you've gone over a bit. Because in Technology the drawings... A little line out of place and you get a grade lower. So when you use computers everything is checked for you so there's less room for criticism, so I prefer using computers for that reason. [GS/12]

In these ways, the capacities of ICT to effect tasks and assist refinement were seen as diminishing the scope for experiences discouraging to pupils. However, pupils also suggested that ICT tools can limit the user's sense of capability and accomplishment in carrying out tasks. Many identified this as a negative feature:

When you, say, do a formula in Maths on the computer, after you've done it you might have got the right answer but you don't feel good about it, whereas if you've done it by hand there's a certain amount of achievement that you feel because you've managed to do it yourself without just relying on the computer to do it. You also get a lot more confidence from doing it because you think I can do this for myself without relying on the computer to do it. $[\mathrm{TC} / 10]$

Likewise, some students enjoyed what they experienced as the independence and autonomy of internet research:

It's nice to find the information for yourself and look it up. You look more at it and you get more information out of it [GS/10]

For others, however, lack of appropriate research skills meant that the sheer volume of information available could be daunting:

It gives you loads of addresses and then you don't know what to pick out so you just end up not bothering. [GS/12]

Equally, the information sources located could make excessive demands on pupils' reading skills:

Words I don't understand. They're really, really long and you don't know what they mean and so you can't write them down in your own words because you can't understand them. $[\mathrm{CC} / 8]$

Here, then, experiences of ICT use ill matched to pupils' capabilities were correspondingly associated with demotivation.

Some comments suggested that interest and motivation associated with use of ICT were translated into harder work and better recall:

It encourages you to do more work. It's less distracting. I'm more encouraged to work harder on it and it sticks in your mind. [MC/10]

Others pointed to a changed quality of engagement:

You kind of concentrate more on the computer because you want to get it right and get it neat, but by hand you just want to get it done because it just gets boring. [GS/8]

In summary, pupils associated ICT use with raised interest and increased motivation on their part. Such views echo the findings of many researchers (for example, Watson et al., 1993; Cox et al., 1997). Interactive courseware was popular amongst pupils particularly games and simulations seen as combining practical challenges with learning opportunities. Some comments suggested that such interest and motivation led not just to harder work on the part of pupils but to a changed quality of engagement. Pupils also saw ICT tools as helping to overcome difficulties they experienced in producing work to a good standard - notably where this involved scribing by hand - so also reducing scope for criticism by teachers. Equally however, without the capacities required, ineffective use of ICT tools could be highly demotivating to pupils. For some pupils, too, use of ICT tools could diminish the sense of capability and accomplishment they gained from carrying out tasks without assistance. 


\section{Learning reshaped}

This theme concerns the contribution of ICT use to reshaping learning. Pupils commented about a spectrum of types of courseware, and noted the way in which other ICT resources had potential to be used not 'as just a tool' but 'as something to learn with'.

Pupils in every school were enthusiastic about revision software and websites, seen as addressing learning objectives simply and directly:

They're simplistic. They didn't come out with all this jargon and everything. They just said the simple question, what you needed to do, and then you go on to the tests and you can do it. I mean, I improved from Year 9 to Year 11 so much. [VC/12]

Equally, pupils appreciated the way in which such resources provided immediate feedback identifying specific areas of weakness:

It tells you the results straight away, so you know what to revise and why. [GS/10]

Likewise, a virtue of courseware was seen as being that:

It's better than books because you can see what's happening on the screen and if you don't understand something you can keep playing it over and over again, but you wouldn't want to keep reading the same thing over and over again because it's boring. [MC/12]

On the computer it's, like, repeating after them and then later on they help you go over it and they keep on going over it until you definitely know what it is and how to spell it and everything. [VC/8]

Such resources were also seen as providing an opportunity for independent working, which some pupils considered helpful in permitting individual pacing and personal regulation:

You can do it independently, so you can work at different speeds... It is probably easier to learn... You have it there in front of you, if you like. If you go through it and you just get confused a bit, you can go back to that bit, rather than just the teachers telling you what it is. You've got to ask them again and they can get a bit, sort of, annoyed with that. So, you can just check it for yourself. It's a bit more like teaching yourself because they say you learn more from teaching than you do from being told. [SC/10]

Earlier thematic sections have recorded how pupils saw ICT use as contributing to effecting tasks and modifying productions. However, some comments - on redrafting and experimentation in particular - have hinted at a further potential for helping pupils to 'think about [their] ideas' or 'compare relationships'. Pupils reported that forms of experimentation, in which they were able to trial changes to a situation and observe their effects, enhanced their grasp of 'what was going on':

It was electron acceleration or something. Rather than show a picture from a book he was able to show us a simulation of what was going on and so I think that helped quite a lot. / We had to type in different values for a magnetic field and electron charges and you could see what had happened and what you did. That definitely helped. [MC/12]

Pupils suggested that use of ICT could allow them to engage more directly with challenging tasks, without some of the potentially frustrating or discouraging 'overheads' of other kinds of practical activity:

On the computers it's like a practical lesson. There are two jugs and you have to tip them and see what can push the energy up and things like that. It's like a practical but if you did it in a practical it would be too messy and it's easier on the computer because you don't get all wet. It does help you because I find the practical easier than writing because you learn more by looking at all the different ways it can be done and if you go wrong on the computer it says 'sorry, try again' and you try again, but if you did it in a real practical you'd get a bit frustrated but on the computer it's a challenge for you because you think once you've started you keep going to get it right and because you're timed it makes you think quicker. [GS/8] 
Likewise, pupils pointed to the way in which, by taking over subordinate tasks, use of ICT could free their attention to focus on overarching issues:

Well, if you're heating water to make it boil the temperature will rise, and then when it's actually boiling it will go flat, it will stay the same for a while, then it will start rising again after it's boiled. So on the graph you can see that actually happening and you can remember that... You could actually see it happening, as it boiled the temperature stayed the same and then it got hotter / It was quite useful because instead of keeping a check on the time and worrying about how long it's been, you can actually concentrate on what it's doing as opposed to how long it's taken. [SC/10]

This idea of ICT helping to 'see [things] actually happening' was also an important one for pupils. They pointed to the value of immediate, dynamic representations in forming powerful images of a changing situation under study:

Well, I suppose with the graph you're watching it as it forms in front of you... Say you were to do it by hand. You do the graph up after you've actually taken down the results. Until you make up the graph you've just got loads of seemingly meaningless figures. As you're doing it on computer you're actually watching the figures plot into a pattern in front of your eyes, so you're actually understanding it sooner than you would just by looking at a load of figures on a sheet of paper. [TC/10]

Nevertheless, other comments indicated that pupils were sensitive to ways in which potential benefits of ICT tools in supporting learning could be missed. For example, while the status of the Internet as a powerful source of information was widely acknowledged, some pupils were more tentative about how effectively they assimilated the information it provided:

Basically you're just printing it out, sticking it straight down on paper and you're not actually taking it in. It's already all there, all the stuff you need, you can just find all of it out and put it down on paper without actually learning it as much. [TC/10]

Similarly, pupils noted how wordprocessor checking facilities could be used mechanically and uncritically:

The spell-check I find I tend to just whiz through it, change, change, change, so I don't actually see how my spelling is actually wrong or how it's been corrected; I don't pay any attention to it. [GS/12]

And while pupils reported that certain operations were eased by using technology, some were sceptical about whether this assisted their learning of the topic at hand:

It's much easier to do it on computer, but maybe you don't actually learn so much about the relationships of that particular graph, you know, about the comparisons, and I think it's important to learn. [CC/10]

Behind such concerns lay a contrast - made explicit in one comment - between using technology effectively 'as just a tool' or more thoughtfully 'as something to learn with':

It depends whether you're using it as something to learn with or using it as just a tool. Because if you're just typing things out on Word that doesn't do much, but if you're using things like the spreadsheets where you actually have to work out the calculations needed... then that can work because it's something to help you learn, like the calculations and things. But normally if you're just typing work up that you've written down or that you just need to neaten up then I don't think it really helps teach you. [TC/10]

In summary, pupils were concerned to 'get a grip on what was puzzling them' (Rudduck et al., 1994); they were aware of, and attached importance to, the security of their own understanding. Pupils were correspondingly appreciative of courseware which addressed learning objectives simply and directly, which provided immediate feedback identifying specific areas of weakness, and which gave opportunity for independent working, individual pacing and personal regulation. Similarly, pupils saw ICT as providing a medium through which they could engage more directly with challenging tasks, devolving the demands of subordinate tasks so as to free their attention for 
overarching issues. They found that forms of experimentation, in which they were able to trial changes and observe their effects, enhanced their understanding of situations. They also valued the contribution that immediate, dynamic representations played in forming powerful images of situations. Both of these features of ICT helped make observable to them what otherwise would be invisible (Snir et al., 1995, Saljo, 1997). Pupils were also sensitive to ways in which the potential benefits of ICT in supporting learning could be missed, particularly if used wholly mechanically and purely instrumentally.

\section{Teaching displaced}

This theme associated ICT use with a degree of distancing and displacement of teachers and teaching and arose first in responses to a question about whether teachers taught differently when they used ICT in the classroom.

Pupils suggested that the collective interactions that normally characterised classroom experience were largely absent from lessons using computers:

When you're in a class, teaching a subject, the whole group is involved. When you're in IT I find it's always individual, she'll come round individually and teach individually. [GS/10]

Whilst accepting this more autonomous way of working, pupils in all year groups said that they still wanted teachers to be readily available to give help where needed:

You know, it's important that they're there if you do have a problem or something goes wrong on the computer and you don't know how to sort it out. [VC/12]

However, they were often frustrated at the amount of time they could spend waiting for help:

So they're really busy going around teaching other people, helping other people, maybe something's gone wrong with the computer so, you know, you're going to have to wait a long time for them to come round and tell you to do something. [GS/10]

To help combat these delays, teachers often enlisted pupils' expertise:

Because I have got a computer at home and I understand most of the work and I end up having to help all the rest of them when I have finished. [GS/8]

Beneath these patterns, pupils detected some unease with computers on the part of teachers:

They seem to be nervous around them because maybe they're not too sure how to use them. [GS/8]

Limitations in technical skill were contrasted with teachers' subject expertise:

The teachers sometimes have to ask you what to do. Say, if there's a problem with a computer they have to ask someone who knows quite a bit about computers what to do. Whereas in the lesson they wouldn't have to do that, there wouldn't be that problem. [SC/10]

Such uncertainty, in turn, was seen to affect the quality of explanations:

Sometimes the teachers aren't quite sure what they're doing on the computers so it's more difficult for them to explain, which just confuses you further [TC/10]

Pupils in all year groups across schools felt strongly that their teachers should be technically confident:

I'd like it if all teachers had to be like an IT teacher. They could still just be an English teacher but they'd know a lot more about the computers. [VC/8]

Pupils often associated lessons involving ICT with a degree of withdrawal on the part of teachers:

They write instructions on the board or they just say 'Today you've got to make a poster about whatever', and then they just leave you to do it. [CC/8]

They regretted loss of opportunities for coaching and discussion about their work: 
So he gave us our task and then we just did it and then he just left us. So if we'd been in the classroom doing that he'd have been giving us tips and telling us things and, you know, we'd have discussions. [MC/10]

Such withdrawal was attributed not only to lack of teacher confidence with technology, but to other factors:

The computer tells you what to do, so he thinks. Well, you know, unless someone waves their hand because they're completely stuck, then he goes and helps, but he sits there and gets his marking done. I think its easier for them because they still have to concentrate on the class, but not as much, you know, they're still teaching you, but. [TC/8]

Similar issues arose when pupils anticipated the future of schooling. They imagined pupils staying at home, connected to a virtual world where lessons arrived electronically and were completed independently. There was little enthusiasm for working in this manner:

Well, it could get to the point where no one has to come to school, all they have to do is sit in front of a computer and type in and the computer teaches them. But it's not personal, and the thing about computers is that it stops you interacting with people and building up relationships with them, so therefore you're missing out on that whole communication part of life. [TC/10]

The importance of being with other people, learning with and from them, was emphasised by many pupils:

I think its important to learn with other people. I sort of think that's what school is, learning from other people, not at home by yourself. You're developing your own self whilst doing so. / In school you do learn from the teachers but you also learn from other pupils, and what their methods of doing things are. [CC/10]

Comments across schools and year groups emphasised the importance of school as a forum for social interaction and support and for the development of social skills:

I think you need a class where you can learn off each other as well and help and support each other. There's other skills you can build on like socialising and stuff in school. I think you need that as well. [MC/12]

Pupils also emphasised the importance of personal assistance from a teacher:

I think it might actually make it harder to learn, because, okay, the more able students would be able to do it by themselves, but some people need personal help from the teachers and it's nice to have them helping you if you just don't understand something. [SC/10]

Equally, opportunities for more informal consultation were considered important:

It's not the same as having a teacher in front of you because you can't talk to them after the lesson, ask the teacher additional questions or speak to them about things that you don't really understand or things like that. [TC/8]

Many pupils pointed to the role of teachers in regulating and structuring academic work:

I don't think it would work because there'd be too much freedom. A lot of people wouldn't bother if they didn't have someone chasing them up or a teacher there. They could get away with doing the least amount of work. If it was like that, you'd have to want to learn. [MC/12]

Here again, the 'personal presence' of a teacher was seen as crucial:

You don't have the personal presence there. It would totally change the way that you'd react. I think a living, breathing teacher commands more respect than a hologram. [SC/10]

In short, teachers were seen as relating to pupils in distinctively human terms:

[Teachers] when they were our age... they've got the memories of it, you know, and we can actually sit there and listen and feel what they're talking about, their experiences. [GS/10]

In summary, pupils were apprehensive about what they saw - actually and potentially - as a diminishing contribution of teachers to their activity. Currently, the more individualised patterns of activity in lessons conducted in ICT classrooms meant that pupils had relatively little interaction with the teacher, and that support was often not as 
readily available as they wished. Pupils saw such trends as being exacerbated where teachers lacked technical confidence and treated computer-based activities as being selfexplanatory. Potentially, pupils imagined teachers becoming still further removed, in a future where pupils would work independently at home. This led pupils to assert the importance of social facilitation in learning, particularly the role of teachers in regulating, structuring and supporting academic work, and the distinctively human qualities and personalising capacities that they brought to such tasks. Likewise, previous English research on pupils' views has pointed to the key role of the teacher in animating pupil engagement and learning. There, pupils saw successful lessons as those well prepared and led by a teacher signalling to pupils an enjoyment of teaching the subject and of teaching it to them. (Rudduck, 1996).

\section{DISCUSSION}

Looking across the three year groups in the six schools represented in our study, we gained a broad picture of the kinds of contribution that pupils saw the use of ICT as making to teaching and learning, and also of some of their reservations about such use.

The first theme, tasks effected, illustrated how pupils viewed ICT tools as enabling them to carry out tasks easily, rapidly and reliably and to present neat and attractive products. The second, refinement assisted, emphasised the ways in which these tools facilitated the progressive editing and revision of written work and exploratory development of ideas and designs. The third theme, ambience altered, revealed that many pupils regarded computer use in school as typically distinct from regular classroom activity in terms of novelty, location, layout and interactions between themselves and their teachers. Elements from these three themes were also closely intertwined with the fourth theme, motivation changed. Whilst pupils associated using ICT with difference, fun, enjoyment, challenge and the removal of constraints associated with manual tasks, they also pointed to attenuated personal satisfaction when automated processes removed the opportunity for their active involvement with the task in hand. Similar reservations were identified within the first theme where pupils felt that uniformity of output detracted from individual creative expression. Motivation was also reduced where inadequate technical skills inhibited pupils' participation in computer-based activities particularly when these involved considerable keyboard input.

The fifth theme, learning reshaped, highlighted ways in which pupils distinguished between using ICT as an expedient production tool and 'something to learn with'. In the latter case, dynamic visual representations and interactive models and simulations enabled clearer focus on, and understanding of, the topics in question; courseware that offered self-paced opportunities for reiteration or practice provided effective means of identifying and repairing knowledge gaps. Yet, resonant with earlier themes, pupils were concerned that, for some operations (especially in Maths and Science), powerful processing tools could inhibit as well as strengthen understanding. The final theme, teaching displaced underlined pupils' apprehensions about the impact of ICT on both the level and quality of teacher-pupil interactions and emphasised the significance of the teacher's role in orchestrating the academic, technical and social aspects of classroom experience.

Much of what the pupils had to say is consistent with findings of other studies undertaken in secondary schools (such as those cited earlier in this paper) - and mirrors views expressed by other groups with a concern for this issue. However, little research has engaged directly with pupils in a way that enables them to express - individually and 
collectively - their perceptions of the impact of ICT on subject teaching and learning. Focus group interviews allowed us to gather a substantial body of such data. The views emerging within - and across - these groups serve to indicate issues of common agreement and concern; and it is these that we have presented here. What they reveal may offer important insights for the schools themselves, for other schools like them, and inform professional thinking more generally.

Pupils' enthusiasm for using ICT at school was tempered by three major considerations: firstly, that wider skills are needed in order to make effective use of the tools available; secondly, that the power of technology must be strategically focussed if it is to enhance subject teaching and learning; and thirdly, that as familiar patterns of classroom interaction are shifted by the introduction of technology, teachers remain central to the provision of structure and support.

A great diversity of technical skill levels existed amongst pupils. Whilst some picked up technical knowledge in an 'ad hoc' fashion by 'tinkering' at home, others lacked such interest or opportunity; but pupils across all groups felt it was important to extend their current skills - not only to facilitate present computer use but to prepare for future working life. Many wished that regular ICT lessons could be provided - and given equal status with other core subjects such as English and Maths; some recognised the need to acquire wider information-handling skills - especially relating to Internet research; others thought that better working knowledge of software and equipment (eg graphic calculators and spreadsheets) would enable them to apply technology more effectively in their studies.

We were struck that, whilst pupils acknowledged ways in which technology could facilitate production of their work - effecting tasks and enabling refinements, they rarely perceived these as directly benefiting learning: 'it doesn't help you learn'. They expressed similar reservations about using technology where they saw it providing a fast track that by-passed opportunities for mental processing and challenge (eg in Maths). Pupils in all schools noted the anomaly of situations where use of technology was promoted in lessons but prohibited in examinations. However, their concerns about relying on technology at the expense of gaining procedural knowledge were not linked primarily with successful performance in future assessments, but emphasised the more immediate personal rewards of successful engagement with the processes of learning.

It is the pursuit and achievement of these motivational rewards that can energise pupil development and progress - and it is here, we suggest, that technology may offer the greatest potential to empower advancement. The teachers' role is therefore crucial in carefully devising strategies which harness the properties of technology to match and support learning goals and objectives eg releasing learners from constraints of manual operations - in order to focus on specific aspects of the topic under consideration; enabling development of ideas by trialling and model building; providing vivid, dynamic - and interactive - simulations and illustrations to aid critical analysis and understanding of objects or phenomena; enabling learners to pace and consolidate their learning eg by purposeful use of designated courseware and revision sites; introducing electronic sources of information and helping learners to select and use material appropriately.

A recent report by Ofsted (2002) concludes that it is 'the effective application of ICT across subjects that needs to improve most'. It also urges schools to 'develop a curriculum that builds on pupils' ICT experiences outside school that contribute to their ICT competence'. Cooper \& McIntyre (1996) observed that learning opportunities are heightened when teaching strategies are transactional - when pupil and teacher concerns 
and interests are integrated, subject knowledge is integrated with other knowledge and made accessible by a variety of means. Technology has added considerably to possible strategies for learning out of school - and supporting learning in school (OECD, 2001) and pupils' increasing use of home computers for games, research, homework and communication - within friendship circles and beyond - may indeed offer promising avenues for the development of motivating and authentic learning activities.

However, pupils in our study were concerned about the extent to which, in future, teaching might become devolved from classroom settings by the adoption of more remote, digitally-based modes of delivery. They signified how work on technologybased tasks often resulted in reduced interactions with their teachers (eg more individualised patterns of activity) and how 'norms' of classroom society were altered when pupils with good technical skills became expert advisers - to teacher and peers alike. The diversity of technical experience pupils now bring to the classroom poses considerable challenge for teachers in designing and supporting technology-enhanced activities, particularly where teachers themselves lack confidence in using ICT. Enlisting technically-skilled pupils as peer tutors may provide a useful solution. However, pupils in our study clearly valued personal assistance from their teachers when needed - and importantly, felt that teachers should be competent and confident in both technical and subject knowledge if technology was to be used effectively in lessons.

Technology has the potential to both enhance and disturb the social interactions upon which the processes of learning primarily depend (Noss and Pachler, 1999); accounts provided by pupils in our study are illustrative of the opportunities and tensions that ICT presents - and further serve to highlight the teacher's essential role in adaptively managing its use. Many of the subject teachers whom we interviewed during the first phase of our study were well-disposed towards using ICT in their teaching - and were exploring, albeit cautiously, ways of utilising various forms of technology within their lessons (Hennessy et al, submitted). Analysis of data from group interviews in Mathematics departments has provided a tentative model of successful use of ICT to support teaching and learning (Ruthven \& Hennessy, 2002). The process of accommodating ICT into classroom practice may lead teachers towards assuming different - and sometimes unaccustomed - ways of working; interim periods of adjustment may be uncomfortable for teachers and pupils alike - and this, perhaps, in measure, accounts for both the pattern of 'cautious adoption' (Kerr, 1991) evidenced by the teachers, and the commensurate 'cautious welcome' displayed by pupils in our study.

Few practitioners and policy makers would disagree that technology offers a range of powerful tools, which proficient users can employ to achieve an impressive array of outcomes; but attention to the pupil voice may help us to determine how - and where judicious pedagogical exploitation of such tools can be most advantageous to the learner.

Note:

During the second phase of our project, 19 teacher-researchers in five of the six research partnership schools - supported by the University research team - undertook research projects that focussed on developing a variety of technology-integrated pedagogical strategies to support subject learning with ICT across the curriculum. Summaries of these studies and teachers' own reports of their research are available on the TiPS [Technology-integrated Pedagogical Strategies] (2001) website; an overarching analysis of the case studies will be reported elsewhere. 


\section{Acknowledgements}

Thanks to Sue Brindley, Chrystalla Petridou, Louise Goodwin and Alison Miller for their various contributions to carrying out this study; and to the Wallenberg Research Centre for Educational Improvement for supporting the project.

\section{References:}

ABBOTT, C. (2001). ICT: Changing Education, London, Routledge.

Becta (2001). Impact2: Emerging Findings from the Evaluation of the Impact of Information and Communications Technologies on Pupil Attainment, London, DfES.

BLAIR, T. (1997). Connecting a Learning Society, http://www.becta.org.uk/start/agfl.html

BLATCHFORD, P. (1996). 'Pupils' views on school work and school from 7-16 years', Research Papers in Education, 11, 263-288.

BRINDLEY, S. (2000). 'ICT and Literacy', In: N. GAMBLE \& N. EASINGWOLD (Eds) Information and Communications Technology, Media, Reading and Writing, London, Continuum.

BROWN, S. \& McINTYRE, D. (1993). Making Sense of Teaching, Milton Keynes, Open University Press.

COOPER, P. \& McINTYRE, D. (1996). 'The importance of power-sharing in classroom learning', In: M. HUGHES (Ed) Teaching and Learning in Changing Times, Oxford, Blackwell.

COX, M. (1997). The effects of Information Technology on Students' Motivation, Coventry, NCET and Kings College.

DOORNEKAMP, G. (1993). 'Students valuation of the use of computers in education', Computers \& Education, 21, 1-2, Jul-Sep 93.

FACER, K., FURLONG, J., FURLONG, R. \& SUTHERLAND, R. (2001). 'Constructing the Child Computer User: from public policy to private practices', British Journal of Sociology of Education, 22, 1, 91-108.

FURLONG, J., FURLONG, R., FACER, K. \& SUTHERLAND, R. (2000). 'The National Grid for Learning: a curriculum without walls?', Cambridge Journal of Education, 30, 1, 91-110.

GILSTER, P. (1997). Digital Literacy, New York, Wiley.

GLASER, B.G. \& STRAUSS, L.L. (1967). The Discovery of Grounded Theory: Strategies for Qualitative Research, Chicago, Aldine.

HARRIS, S., WALLACE, G. \& RUDDUCK, J. (1995). 'It's not that I haven't learnt much. It's just that I don't really understand what I'm doing'; metacognition and secondary-school students, Research Papers in Education, 10, 2, 253-271.

HOLLOWAY, S. \& VALENTINE, G. (1999). The Cyberkids report, Loughborough, Loughborough University.

HENNESSY, S., RUTHVEN, K., \& BRINDLEY, S., (submitted). 'Teacher perspectives on integrating ICT into Subject Teaching: Consensus, Caution and Change'.

KEYS, W. \& FERNANDES, C. (1993). What do students think about school?, Slough, NFER.

KERR, S. (1991). 'Lever and Fulcrum: Edcuational Technology in Teachers' Thought and Practice', Teachers College Record, 93, 1, 114-136.

KITZINGER, J. \& BARBOUR, R. (1999). Developing Focus Group Research Politics, Theory and Practice, London, Sage.

LEACH, J. \& MOON, B. (2000). 'Pedagogy, information and communications technology and teachers' professional knowledge', The Curriculum Journal, 11, 3, 385-404.

LORD, P. \& HARLAND, J. (2000). Pupils' Experiences and Perspectives of the National Curriculum: Research Review, QCA.

McCALLUM, B., HARGREAVES, E. \& GIPPS, C. (2000). 'Learning: the pupil's voice', Cambridge Journal of Education, 30, 2, 275-288.

NORRIS, C., SMOLKA, J. \& SOLOWAY, E. (1999). Convergent Analysis: a method for extracting the value from research studies on technology in education, http://www.ed.gov/technology/techconf/1999/whitepapers/papers2.html

NOSS, R. \& PACHLER, N. (1999). 'The Challenge of New Technologies: Doing Old Things in a New Way, or Doing New Things?', In: P. MORTIMORE (Ed) Understanding Pedagogy and its Impact on Learning, London, Paul Chapman.

ORGANISATION FOR ECONOMIC CO-OPERATION AND DEVELOPMENT (2001). Learning to Change: ICT in Schools. Paris, OECD. 
OFFICE FOR STANDARDS IN EDUCATION (2002). ICT in Schools: Effect of Government initiatives. London. OFSTED.

PACHLER, N. (1999). 'Theories of Learning and ICT', In: M. LEASK \& N. PACHLER (Eds) Learning to Teach Using ICT in the Secondary School, London, Routledge.

PEDRETTI, E., MYER-SMITH, J. \& WOODROW, J. (1998). Technology, Text and Talk: Student Perspectives on Teaching and Learning in a Technology-Enhanced Secondary Science Classroom, Science Education, 82, 5, 569-589.

POLLARD, A. \& TANN, S. (1993). Reflective teaching in the primary school: a handbook for the classroom, London, Cassell.

RUDDUCK, J., CHAPLAIN, R. \& WALLACE, G. (1996). School improvement; what can pupils tell us?, London, David Fulton.

RUDDUCK, J. \& FLUTTER, J. (2000). 'Pupil Participation and Pupil Perspective: 'carving a new order of experience', Cambridge Journal of Education, 30, 1, 75-88.

RUDDUCK, J., HARRIS, S. \& WALLACE, G. (1994). “'Coherence' and Students' Experience of Learning in the Secondary School', Cambridge Journal of Education, 24, 2, 197-211.

RUSHKOFF, D. (1997). Children of Chaos, London, Harper Collins.

RUTHVEN, K. \& HENNESSY, S (2002). 'A Practitioner Model of the Use of Computer-based Tools and Resources to support Mathematics Teaching and Learning, Educational Studies in Mathematics, 49, 47-88

SELWYN, N. (1997). 'Assessing Students' Ability to Use Computers: theoretical considerations for practical research', British Educational Research Journal, 23, 1, 47-59

SALJO, R. (1999). 'Learning as the use of tools: a sociocultural perspective on the human-technology link', In: K. LITTLETON \& P. LIGHT (Eds) Learning with Computers:analysing productive interaction, London and New York, Routledge.

SNIR, J., SMITH C., \& GROSSLIGHT, L. (1995). 'Conceptually enhanced simulations: a computer tool for science teaching' in D. N. PERKINS, J. L. SCHWARTZ, M. M. WEST \& M. S. WISKE (Eds), Software Goes to School. Teaching for Understanding with New Technologies, New York, Oxford University Press

TiPS [Technology-integrated Pedagogical Strategies] (2001). www.educ.cam.ac.uk/TiPS/tips1.html

UNDERWOOD, J. (1998). 'Making Groups Work', In: M. MONTEITH (Ed) IT for Learning Enhancement, Exeter, Intellect Books.

WATSON, D., COX, M. \& JOHNSON, D. (1993). The ImpacT Report, London, Kings College.

WELLINGTON, J. (2001). 'Exploring the Secret Garden: the growing importance of ICT in the home', British Journal of Educational Technology, 32, 2, 233-244. 